\title{
Cultivo de gladíolos em função das doses de calcário e potássio
}

\author{
Elisa F Bratti²; Yara BCJ Rosa²; Eulene F Silva³; Edgard J Rosa Júnior²; Néstor AH Zárate²; Guilherme \\ A Bíscaro ${ }^{2}$; Derek BCJ Rosa ${ }^{2}$
}

2UFGD-FCA, C. Postal 533, 79804-970 Dourados-MS; elisafelt@yahoo.com.br; yararosa@ufgd.edu.br; ${ }^{3}$ UFERSA-DCAT, Av. Francisco Mota 572, 59625-900 Mossoró-RN

\section{RESUMO}

Para o cultivo do gladíolo no Cerrado, caracterizado por solos de baixa fertilidade e elevada acidez, faz-se necessário o uso de corretivo agrícola e fertilização, especialmente a potássica. Assim, o objetivo desta pesquisa foi avaliar o efeito de diferentes doses de calcário e de potássio na produção comercial de plantas de gladíolo, cultivadas em um Latossolo Vermelho Distroférrico. O experimento foi conduzido na UFGD, em Dourados (MS). O delineamento experimental constou de blocos casualizados com quatro repetições, sendo que a unidade experimental foi composta por duas plantas de gladíolos, cultivar Peter Pears, cultivadas em vaso plástico de $5 \mathrm{~L}$. Os tratamentos foram arranjados em parcelas subdivididas, sendo que nas parcelas foram alocadas as cinco doses de calcário dolomítico $\left(0,1,2,4\right.$ e $\left.8 \mathrm{t} \mathrm{ha}^{-1}\right) \mathrm{e}$, nas sub-parcelas, as cinco doses de $\mathrm{K}_{2} \mathrm{O}\left(0,20,40,80\right.$ e $\left.160 \mathrm{~kg} \mathrm{ha}^{-1}\right)$, utilizando-se como fonte o cloreto de potássio $(\mathrm{KCl})$. Determinaram-se o comprimento das folhas, o início da floração, a durabilidade e o número de botões florais, a altura da planta e o comprimento das espigas. Após a floração, avaliou-se a matéria fresca, comprimento e diâmetro dos cormos produzidos e o teor de nutrientes da parte aérea. O comprimento das folhas, início da floração e durabilidade dos botões florais não foram influenciados pela calagem nem pela adubação potássica. $\mathrm{O}$ excesso de $\mathrm{K}$ e $\mathrm{CaCO}_{3}$ foram prejudiciais à altura da planta e ao comprimento da espiga floral, reduzindo o número de botões florais e o diâmetro dos cormos produzidos; doses elevadas de $\mathrm{K}_{2} \mathrm{O}$ diminuíram a absorção de magnésio pelas plantas. Conclui-se que as doses de calcário e potássio estudadas não foram eficientes para produzir plantas de gladíolo classificadas comercialmente como extras.

\begin{abstract}
Lime and potassium doses for the Gladiolus grandiflorus cropping in Dourados, Brazil

Cultivation of gladiolus in the Brazilian Savannah (locally known as Cerrado), a biome characterized by low fertility and high soil acidity, requires the use of lime and fertilizer, mainly potassium. The effect of lime and potassium rates was evaluated in the cultivation of gladiolus plants in an Oxisol (Typical Haplustox) from Cerrado, in Dourados municipality, Mato Grosso do Sul state. The experiment was carried out in the Univerdidade Federal da Grande Dourados. We adopted the randomized blocks design with four replications; the treatments were arranged in split-plots and the plots were composed of two plants of gladiolus cultivar Peter Pears, grown in plastic pots of $5 \mathrm{~L}$. Thus, five rates of lime $\left(0,1,2,4\right.$ and $\left.8 \mathrm{t} \mathrm{ha}^{-1}\right)$ were applied to the main plots one month before planting and five $\mathrm{K}_{2} \mathrm{O}$ rates $\left(0,20,40,80\right.$, and $\left.160 \mathrm{~kg} \mathrm{ha}^{-1}\right)$ were applied to the sub-plots, using potassium chloride $(\mathrm{KCl})$ as source. The length of the leaves, beginning of flowering, durability and number of flower buds, plant height and length of floral stalks were determined. After flowering, fresh weight, length and diameter of the corms and the nutrient content of the shoots were evaluated. The length of the leaves, beginning of flowering and durability of the flower buds were neither affected by liming, nor by fertilization with potassium. Excessive $\mathrm{K}$ and $\mathrm{CaCO}_{3}$ doses were harmful to plant height, length of floral stalk and spike, and reduced the number of flower buds and the diameter of the corm. High concentrations of exchangeable $\mathrm{K}$ in the soil decreased absorption of magnesium by the plants. The studied rates of lime and potassium were not efficient for the production of gladiolus plants classified as extra large in the market.
\end{abstract}

Keywords: Gladiolus grandiflorus, floriculture, fertilization, corms.

Palavras-chave: Gladiolus grandiflorus, floricultura, adubação, cormo.

(Recebido para publicação em 7 de março de 2011; aceito em 5 de junho de 2012) (Received on March 7, 2011; accepted on June 5, 2012)

$\mathrm{O}$ gladíolo é planta ornamental utilizada mundialmente em projetos paisagísticos ou cultivada como flor de corte ou para a produção de cormos (Tombolato, 2004). No Brasil tornou-se uma cultura de grande expressão devido ao seu ciclo curto (60 a 120 dias) propiciando rápido retorno ao produtor (Paiva, 1999), sendo que $70 \%$ da produção de suas hastes florais abastecem o mercado interno. Os cormos são utilizados para replantio da cultura ou para exportação (Ruppenthal \& Castro, 2005).

De 2000 a 2008 as exportações brasileiras de flores e plantas ornamentais passaram de US\$11,97 para US \$35,50 milhões de dólares. Durante este período a exportação de bulbos, rizomas e cormos tornou-se cada vez mais significativa e, em 2010, este segmento correspondeu a $46,31 \%$ das exportações do setor, totalizando US\$ 13,28 milhões (Junqueira \& Peetz, 2011). Nesse período, os bulbos mais comercializados foram de gladíolos e amarílis, principalmente fornecidos pelos estados de São Paulo (78,65\%) e Ceará $(21,35 \%)$ e, os principais países consumidores foram Holanda $(83,15 \%)$ e Estados Unidos (14,20\%) (Junqueira \& Peetz, 2011).

Cultivado em vários países, o gla- 
díolo necessita de solos leves, bem drenados, arenosos e com boa aeração para seu desenvolvimento, sendo exigente principalmente em nitrogênio, potássio e cálcio (Tombolato, 2004). Portanto, para seu cultivo na região de Dourados, que está inserida no bioma Cerrado (caracterizado por solos de baixa fertilidade, elevada acidez, e baixo teores de nutrientes como $\mathrm{Ca}, \mathrm{Mg}, \mathrm{K}$ e P), é necessário o uso de corretivo agrícola e fertilização.

A disponibilidade de $\mathrm{K}$ no solo e a sua absorção pelas plantas estão relacionadas com a disponibilidade de cátions bivalentes, principalmente $\mathrm{Ca}$ e $\mathrm{Mg}$ (Medeiros et al., 2008). A deficiência do potássio, especialmente em gladíolos deve ser monitorada, pois causa da redução no número de botões florais, diminuição no tamanho da haste e atraso na floração (Tombolato, 2004). A utilização de adubação suplementar semanal com $25 \mathrm{~g} \mathrm{~m}^{-2}$ de $\mathrm{KNO}_{3}$ até 2 semanas antes da colheita dos cormos antecipou a colheita e aumentou a porcentagem de florescimento, o comprimento e o diâmetro da haste floral e o número de flores por espiga floral da cultura (Karagüzel et al., 1999).

Em contrapartida, Zubair et al. (2006) relatam que a utilização de 200 $\mathrm{kg} \mathrm{ha}^{-1}$ de $\mathrm{K}_{2} \mathrm{SO}_{4}$ atrasou em 20 dias a emissão das espigas florais enquanto que a dose de $100 \mathrm{~kg} \mathrm{ha}^{-1}$ a antecipou em 8 dias em relação ao controle $(0 \mathrm{~kg}$ ha $^{-1}$ ). Além disso, a elevada adubação potássica pode induzir a deficiência de $\mathrm{Ca}$ e $\mathrm{Mg}$ provocando encurvamento das hastes, quebra da inflorescência floral, aborto floral, encurtamento das espigas e atraso no florescimento (Tombolato, 2004)

A deficiência de Ca também pode reduzir a vida pós-colheita dessas flores conforme relato de Sairam et al. (2011) que aumentaram de 5,5 para 9,0 dias a vida pós-colheita de hastes de gladíolos submetidas a soluções de $50 \mathrm{mmol} \mathrm{L}^{-1}$ de $\mathrm{Ca}$ em relação ao controle (água destilada).

A cultura de gladíolos no Brasil iniciou-se por volta de 1950 e, após 60 anos do seu cultivo em escala comercial, poucos são os relatos científicos nacionais que se reportam às suas exigências, sendo que entre eles estão os de
Paiva (1999); Tombolato (2004); Borges (2005); Gimarães et al. (2005); Pontes et al. (2005); Ruppenthal \& Castro (2005) e o de Rosa et al. (2009).

Considerando a importância do $\mathrm{K}$ e Ca para esta cultura, este trabalho foi desenvolvido com o objetivo de avaliar o efeito de doses de calcário e de potássio na produção comercial e nos teores nutricionais de gladíolos, cultivados em Latossolo Vermelho Distroférrico em Dourados.

\section{MATERIAL E MÉTODOS}

O experimento foi conduzido na área de jardinocultura da Universidade Federal da Grande Dourados, em Dourados (MS) (22 $11^{\circ} 45^{\prime \prime} \mathrm{S}$ e $54^{\circ} 55^{\prime} 18^{\prime \prime} \mathrm{W}$, altitude de $446 \mathrm{~m}$ ), de 28 de julho a 31 de dezembro de 2008. O clima é do tipo Cwa mesotérmico úmido, segundo a classificação de Köppen (1948). A precipitação média anual é de $1500 \mathrm{~mm}$ e a temperatura média de $22^{\circ} \mathrm{C}$.

O solo utilizado para enchimento dos vasos foi proveniente de uma área de vegetação nativa coletado na profundidade de 0-20 cm, e classificado como Latossolo Vermelho Distroférrico, cujos atributos químicos foram: $\mathrm{pHCaCl}_{2}=$ 4,$4 ; \mathrm{pHH}_{2} \mathrm{O}=5,3 ; \mathrm{P}=3,0 \mathrm{mg} \mathrm{dm}{ }^{3} ; \mathrm{K}=$ $1,5 \mathrm{mmol}_{\mathrm{c}} \mathrm{dm}^{3} ; \mathrm{Al}=5,5 \mathrm{mmol}_{\mathrm{c}} \mathrm{dm}^{3}$; $\mathrm{Ca}=31,0 \mathrm{mmol}_{\mathrm{c}} \mathrm{dm}^{3} ; \mathrm{Mg}=9,0 \mathrm{mmol}_{\mathrm{c}}$ $\mathrm{dm}^{3} ; \mathrm{H}+\mathrm{Al}=69,0 \mathrm{mmol}_{\mathrm{c}} \mathrm{dm}^{3} ; \mathrm{SB}=41,5$ mmol $_{\mathrm{c}} \mathrm{dm}^{3} ; \mathrm{T}=110,5 \mathrm{mmol}_{\mathrm{c}} \mathrm{dm}^{3} ; \mathrm{V} \%=$ 37. Após a coleta, o solo foi seco à sombra, por 10 dias, sendo posteriormente, peneirado em peneira com malha de 2 mm de diâmetro.

$\mathrm{O}$ delineamento experimental utilizado foi em blocos casualizados com quatro repetições e a unidade experimental foi composta por duas plantas de gladíolos, cultivar Peter Pears, cultivadas em vaso plástico com capacidade para 5 L. Os tratamentos foram arranjados em parcelas subdivididas, sendo nas parcelas alocadas as cinco doses de calcário dolomítico $\left(0,1,2,4\right.$ e $\left.8 \mathrm{tha}^{-1}\right)$ com PRNT de 92\%, e nas sub-parcelas as cinco doses de $\mathrm{K}_{2} \mathrm{O}(0,20,40,80$ e $160 \mathrm{~kg} \mathrm{ha}^{-1}$ ), utilizando-se como fonte o cloreto de potássio $(\mathrm{KCl})$.

Foram adicionados em cada vaso 4,5 $\mathrm{kg}$ de solo juntamente com as doses de calcário supracitadas, sendo as doses de $\mathrm{K}_{2} \mathrm{O}$ adicionadas posteriormente. Após a homogeneização do solo com calcário, a quantidade de água foi adicionada de acordo com a capacidade máxima de retenção de água no solo (AWC), determinada pelo método do funil, que resultou em $30 \%$ do volume total do solo. Sendo assim, nos primeiros 30 dias, cada vaso recebeu duas aplicações semanais de $270 \mathrm{~mL}$ cada, o que correspondeu a $40 \%$ da AWC.

Aos 31 dias após a adição do calcário, em cada vaso, foram plantados dois cormos de gladíolo de número 10/12 (extremos dos perímetros dos cormos), a uma profundidade de $10 \mathrm{~cm}$ (previamente tratados com o fungicida mancozeb 4 $\mathrm{g} \mathrm{L}^{-1} \mathrm{e}$ avaliados quanto à matéria fresca, comprimento e diâmetro). As doses de $\mathrm{K}_{2} \mathrm{O}$ foram divididas em três porções iguais e aplicadas em cobertura aos 20, 35 e 50 dias após o plantio (DAP). Durante o período experimental todas as plantas receberam $60 \mathrm{~kg} \mathrm{ha}^{-1}$ de nitrogênio (fonte uréia) divididos em três porções iguais, aplicadas em cobertura em conjunto com a adubação potássica.

Até o início do pendoamento as plantas receberam semanalmente 720 $\mathrm{mL}$ de água (53,3\% da AWC), divididos em duas aplicações de $360 \mathrm{~mL}$ para minimizar as perdas por evaporação, ocasião em que eram realizados controles manuais das plantas invasoras. Após o pendoamento as plantas receberam semanalmente $900 \mathrm{~mL}$ de água $(66,6 \%$ da AWC divididos em três aplicações de $300 \mathrm{~mL}$ ). Durante todo o experimento foi descontado o volume de água quando houve precipitação pluviométrica, pois os vasos ficaram em pleno sol.

Durante o desenvolvimento da cultura foram feitas mais duas aplicações de mancozeb $\left(4 \mathrm{~g} \mathrm{~L}^{-1}\right)$ aos 45 e 55 dias após o plantio, para prevenção de doenças, principalmente de Botritis (Botryotinia draytonii). Todas as práticas culturais e fitossanitárias seguiram as recomendações de Tombolato (2004). No pendoamento foi medido o comprimento das folhas (distância, em centímetros, entre a superfície do solo e o ápice da folha mais alta) e em seqüência foram registrados o início da floração (número de dias após o plantio para abertura do botão floral basal), número de botões por 
espiga floral, durabilidade (número de dias compreendidos entre a abertura e o murchamento do botão floral basal), altura da planta (distância, em centímetros entre a superfície do solo e a inserção do botão floral apical) e o comprimento das espigas florais (distância, em centímetros, entre a inserção do botão floral basal e do apical). Posteriormente, as plantas foram classificadas em Extra, I, II e III conforme a classificação brasileira de gladíolos para fins comerciais (Bongers, 2000).

Após a floração, as plantas ainda foram mantidas no mesmo local recebendo semanalmente $720 \mathrm{~mL}$ de água divididos em duas aplicações de 360 $\mathrm{mL}$. Decorrido um mês, as plantas foram removidas do substrato e separadas em parte aérea e subterrânea. A parte aérea foi lavada com água deionizada, seca em estufa com circulação forçada de ar à temperatura de $55^{\circ} \mathrm{C}$ e moída, sendo posteriormente, determinados os teores foliares de $\mathrm{N}, \mathrm{K}$, Ca e $\mathrm{Mg}$, para cada tratamento, seguindo os procedimentos de Malavolta et al. (1997). A parte subterrânea, constituída pelos cormos produzidos, também foi lavada com água corrente para remoção do substrato e, com o auxílio de paquímetro digital, os cormos foram medidos em relação ao seu comprimento e diâmetro e pesados para determinação da matéria fresca. Dado o interesse em investigar a hipótese de aumento no comprimento, diâmetro e matéria fresca dos cormos propagados em relação aos plantados foram calculadas suas diferenças e estes valores foram considerados nas análises estatísticas.

Para análise estatística dos resultados utilizou-se aplicativo computacional (SISVAR 5.3) e todas as variáveis foram estudadas mediante análise de variância, sendo posteriormente os fatores quantitativos avaliados por meio de regressão.

\section{RESULTADOS E DISCUSSÃO}

Não houve efeito isolado ou interação $(\mathrm{p}>0,05)$, das doses de calcário e potássio sobre o comprimento das folhas, início da floração, durabilidade e número de botões florais, matéria fresca e comprimento do cormo produzido, e teores foliares de Ca. Efeitos conjuntos dos fatores estudados $(p<0,05)$ foram observados sobre a altura das plantas, comprimento da espiga floral, diâmetro dos cormos produzidos e sobre os teores foliares de $\mathrm{K}, \mathrm{Mg}$ e $\mathrm{N}$.

As folhas apresentaram comprimento médio de $50,5 \mathrm{~cm}$ e as plantas iniciaram a floração aos 72,1 dias após o plantio apresentando 7,0 botões florais por espiga (Classe III de gladíolos para fins comerciais) com durabilidade média de 4,2 dias. Por se tratar de plantas de dias curtos (Tombolato, 2004), o gladíolo tem o estímulo ao florescimento antecipado quando cultivado em locais com menores latitudes e prolongado em maiores latitudes, o que foi comprovado nos trabalhos desenvolvidos por Boyle et al. (2009) em Boa Vista (RR), Brasil $\left(02^{\circ} 49^{\prime} \mathrm{N}\right)$ e por Zubair et al. (2006) em Peshawar-Paquistão (341'ㅅN) que produziram flores da cultivar Peter Pears respectivamente aos 54 e 166 dias após o plantio.

Neste trabalho, realizado em latitude de $22^{\circ} 11^{\prime} \mathrm{S}$, o início do florescimento ocorreu em período intermediário aos

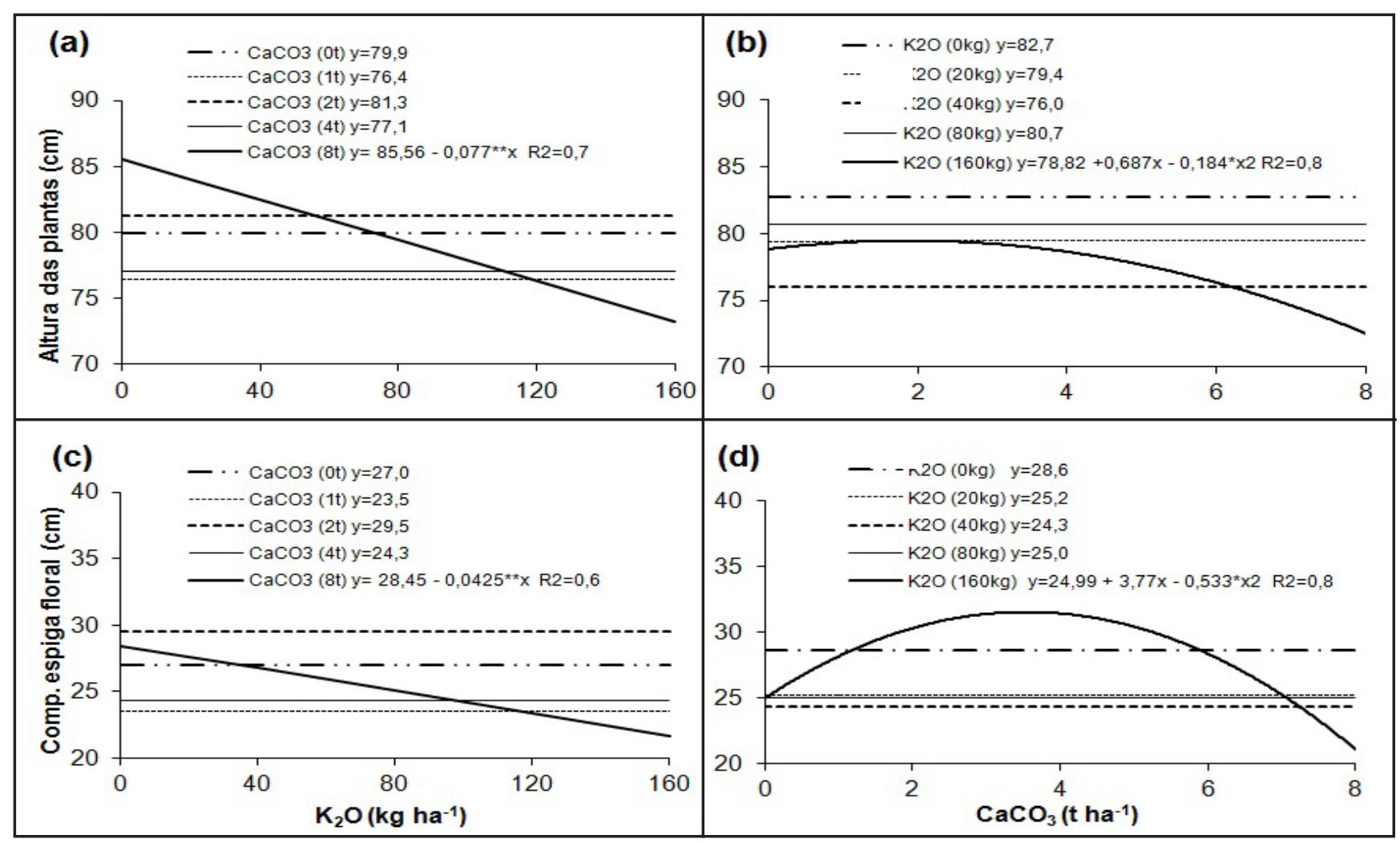

Figura 1. Estimativas da altura de planta $(\mathrm{a}, \mathrm{b})$ e comprimento da espiga floral $(\mathrm{c}, \mathrm{d})(\mathrm{cm})$ de plantas de gladíolo em função da calagem e da adubação potássica (plant height $(\mathrm{a}, \mathrm{b})$ and length of flower spike $(\mathrm{c}, \mathrm{d})(\mathrm{cm})$ of gladiolus plants affected by liming and potassium fertilization). Dourados, UFGD, 2008. 


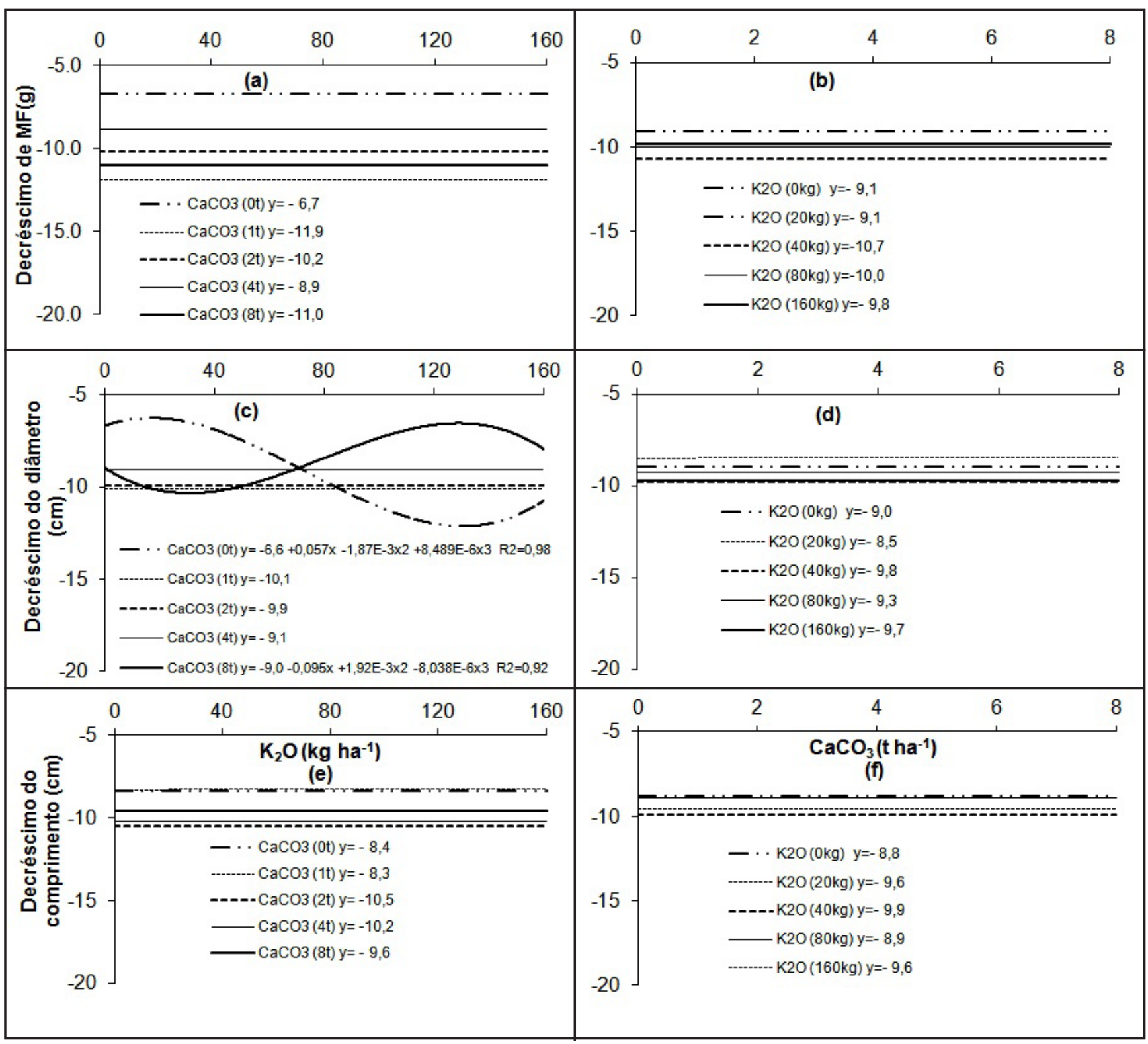

Figura 2. Decréscimo da matéria fresca $(\mathrm{a}, \mathrm{b})$, decréscimo do diâmetro $(\mathrm{c}, \mathrm{d})$ e decréscimo do comprimento (e,f) do cormo de plantas de gladíolo em função da calagem e da adubação potássica (decrease of fresh mass (a, b), in diameter (c, d) and in length (e, f) of the corm of gladiolus plants, affected by liming and potassium fertilization). Dourados, UFGD, 2008.

observados por Boyle et al. (2009) e Zubair et al. (2006) e foi compatível com a cultivar estudada cuja floração inicia, em média, aos 75 DAP. A não observância de efeitos significativos $(\mathrm{p}>0,05)$ das doses de potássio estudadas sobre o início da floração permite inferir que ela deve estar mais relacionada com a latitude do local de cultivo, níveis de luminosidade e a duração do fotoperíodo do que com as doses de potássio estudadas.

Os efeitos conjuntos das doses de calcário e potássio sobre a altura das plantas e comprimento da espiga floral são apresentados na Figura 1.
Desdobrando a interação $\mathrm{CaCO}_{3} \mathrm{x}$ $\mathrm{K}$, observou-se que, quando se analisa o calcário dentro das doses de $\mathrm{K}_{2} \mathrm{O}$, a altura das plantas foi mais influenciada pela calagem do que pela adubação potássica. Com a dose de $8 \mathrm{t} \mathrm{ha}^{-1}$ de calcário sem adição de potássio obteve-se um comprimento de $85,8 \mathrm{~cm}$; no entanto, ao aumentar as doses de $\mathrm{K}_{2} \mathrm{O}$ houve um decréscimo linear na altura das plantas (Figura 1a). Ao analisar o potássio em relação às doses de $\mathrm{CaCO}_{3}$, o maior registro ocorreu sem a adição de potássio $(82,7 \mathrm{~cm})$ (Figura $1 \mathrm{~b})$, sendo que em doses mais elevadas de $\mathrm{K}_{2} \mathrm{O}$ (160 $\mathrm{kg} \mathrm{ha}^{-1}$ ) é necessária a adição de $1,87 \mathrm{t}$ ha $^{-1}$ de $\mathrm{CaCO}_{3}$ (ponto de máximo) para não ser prejudicial à altura das plantas. A altura das plantas obtida neste estudo atinge a Classe II de gladíolos para fins comerciais (Bongers, 2000).

A altura de planta é uma característica muito influenciada pela cultivar e condições climáticas; assim, analisando oito cultivares, Zubair et al. (2006) observaram que as plantas mais altas $(138,0 \mathrm{~cm})$ foram registradas na cultivar Rose Supremo, enquanto que, as menores plantas pertenciam à cultivar White Friendship $(81,8 \mathrm{~cm})$. As demais cultivares situaram-se entre esses dois resultados, inclusive a cultivar Peter 


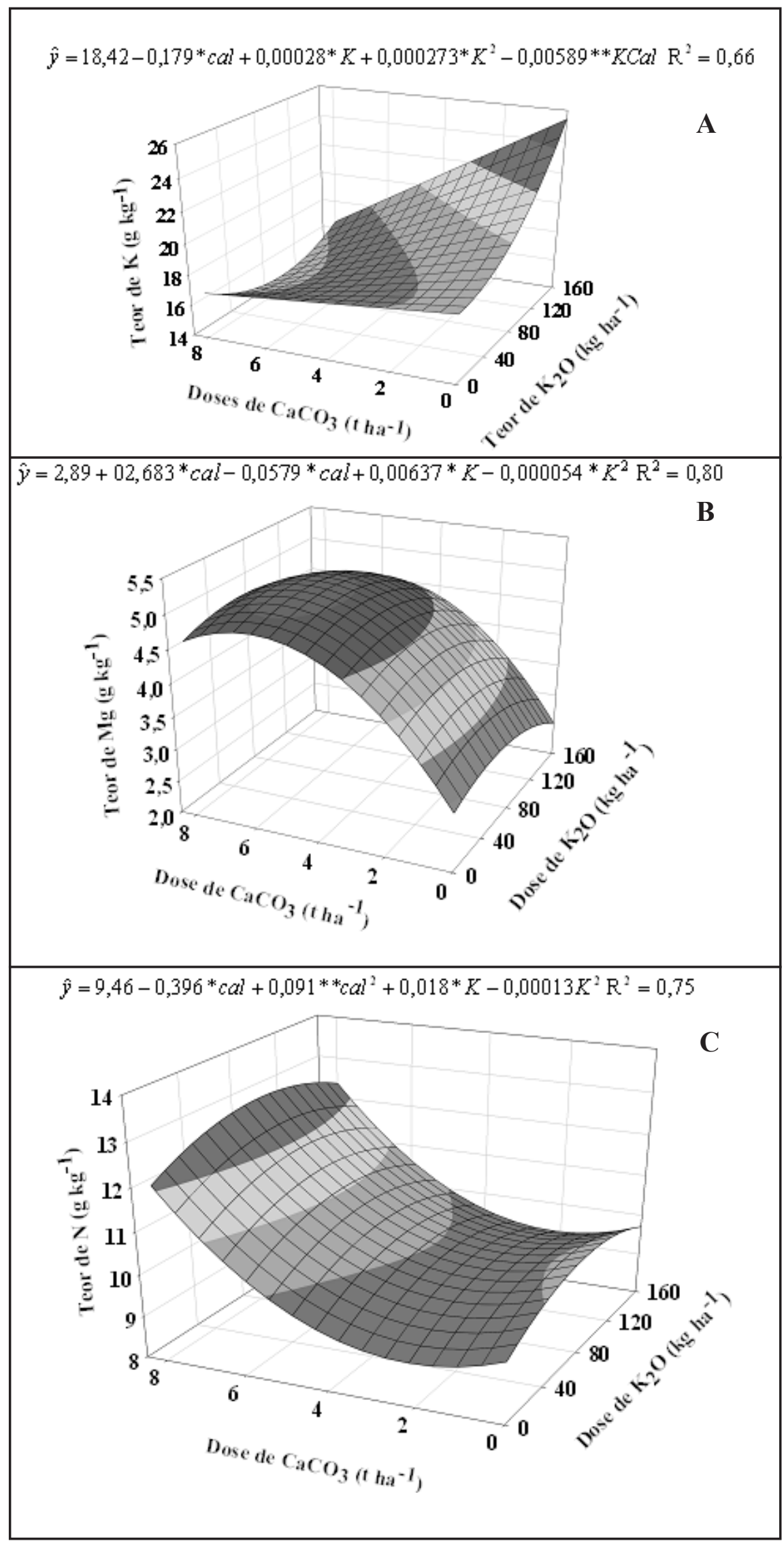

Figura 3. Estimativas foliares dos teores de $\mathrm{K}, \mathrm{Mg}$ e $\mathrm{N}$ em função da calagem e adubação potássica (leaf estimates of $\mathrm{K}, \mathrm{Mg}$ and $\mathrm{N}$ depending on liming and potassium fertilization). Dourados, UFGD, 2008.
Pears, com 107,7 cm. Os autores estudaram três doses de potássio e fizeram uma ressalva, pois apesar da adubação potássica não afetar significativamente a maioria das características de crescimento, ela é aconselhada devido ao seu importante papel na fisiologia da planta.

Ao avaliar as doses de $\mathrm{CaCO}_{3}$ em relação ao $\mathrm{K}$, praticamente não houve diferença entre os tratamentos estudados, sendo a maior média de comprimento da espiga atingida $(29,5 \mathrm{~cm})$ quando a dose de $\mathrm{CaCO}_{3}$ foi de $2 \mathrm{tha}^{-1}$. Contudo, assim como ocorrido com a altura da planta, a dose de 8 tha $^{-1}$ de calcário proporcionou um decréscimo linear no comprimento da espiga com o aumento das doses de $\mathrm{K}_{2} \mathrm{O}$ (Figura 1c). Analisando as doses de $\mathrm{K}_{2} \mathrm{O}$, observou-se um ajuste quadrático, onde o maior comprimento de espiga $(31,7 \mathrm{~cm})$ foi obtido na dose de $160 \mathrm{~kg}$ $\mathrm{ha}^{-1}$ com a dose calculada de 3,54 $\mathrm{tha}^{-1}$ de $\mathrm{CaCO}_{3}$ (Figura 1d).

Embora a coleta dos cormos tenha sido realizada seis semanas após o início da floração, tempo mínimo recomendado por Tombolato (2004), todas as combinações de calcário e potássio propiciaram decréscimos na matéria fresca, no diâmetro e no comprimento dos cormos produzidos em relação aos plantados. Estes resultados indicam que a cultura necessita de um período maior para a colheita, para que as estruturas vegetativas sejam pelo menos iguais àquelas plantadas, ou que as doses testadas não são adequadas a esta finalidade (Figura 2a, b, e, f).

Em relação aos teores foliares de $\mathrm{Ca}$, $\mathrm{K}, \mathrm{Mg}$ e N, observou-se que os teores de cálcio na planta não foram influenciados pela adubação potássica nem pela calagem sendo o teor médio obtido de $16,4 \mathrm{~g} \mathrm{~kg}^{-1}$. No entanto, o aumento da adubação potássica no solo interagindo com a elevação do $\mathrm{CaCO}_{3}$ reduziram de modo significativo os teores de $\mathrm{K}$ na planta, sendo o máximo teor $(25,7 \mathrm{~g}$ $\mathrm{kg}^{-1}$ ) obtido quando da aplicação de 160 $\mathrm{kg} \mathrm{ha}^{-1}$ de $\mathrm{K}_{2} \mathrm{O}$ sem a adição de $\mathrm{CaCO}_{3}$ (Figura 3a). Para os teores de $\mathrm{Mg}$, o máximo teor na planta foi de $5,1 \mathrm{~g} \mathrm{~kg}^{-1}$, observando-se um comportamento quadrático, no qual doses superiores a 58,7 $\mathrm{kg} \mathrm{ha}^{-1}$ de $\mathrm{K}_{2} \mathrm{O}$ e $5,90 \mathrm{t} \mathrm{ha}^{-1}$ de $\mathrm{CaCO}_{3}$ reduziram significativamente a absorção deste nutriente pela planta (Figura 
$3 b)$. No estudo de correlações $(\mathrm{p}<0,05)$ observaram-se correlações negativas entre $\mathrm{Ca}$ e $\mathrm{K}(-0,68)$ e, $\mathrm{K}$ e $\mathrm{Mg}(-0,88)$, e positiva entre $\mathrm{Ca}$ e $\mathrm{Mg}(0,60)$.

A aplicação de altas doses de fertilizante potássico pode provocar desequilíbrio nutricional nas plantas, evidenciando o efeito antagônico do $\mathrm{K}$ em relação à absorção, tanto do Ca quanto do $\mathrm{Mg}$, visto que todos são nutrientes catiônicos que competem fortemente pelos mesmos sítios de absorção (Malavolta et al., 1997; Mascarenhas et al., 2000). A competição entre nutrientes por sítios de troca da membrana plasmática das células radiculares acontece particularmente entre íons com propriedades fisico-químicas semelhantes, como o $\mathrm{NH}_{4}^{+}$que, em algumas situações, inibe a absorção de $\mathrm{K}^{+}$pelas raízes, ou no caso do $\mathrm{Mg}^{2+}$, que sofre forte competição por sítios de troca do tecido radicular com o $\mathrm{Ca}^{2+}$ e o $\mathrm{K}^{+}$e vice-versa (Marschner, 1995).

Doses mais elevadas de calcário podem promover modificação drástica da relação $\mathrm{Ca}: \mathrm{Mg}$, ocasionando um desequilíbrio de nutrientes, ou seja, a medida que essa relação aumenta, ocorre antagonismo na absorção, especialmente para magnésio e potássio podendo prejudicar a absorção de K (Marschner, 1995). Neste experimento, a calagem promoveu o aumento das concentrações de $\mathrm{Ca}$ e $\mathrm{Mg}$ do solo e reduziu a absorção do $\mathrm{K}$, sendo o efeito antagônico mais pronunciado para o $\mathrm{Mg}$ e $\mathrm{K}$.

Para os teores de N na planta de gladíolo, observou-se um ajuste quadrático para os dados com ponto de mínima para calagem e ponto de máxima para $\mathrm{K}$ (Figura 3c). Isto significa que doses de $\mathrm{K}_{2} \mathrm{O}$ acima da dose calculada de $88 \mathrm{~kg} \mathrm{ha}^{-1}$ foram prejudiciais para absorção de $\mathrm{N}$ na planta. Todavia, para a calagem, doses superiores a 2,05 $\mathrm{t} \mathrm{ha}^{-1}$ favoreceram a absorção do $\mathrm{N}$ pela planta, obtendo um teor de $\mathrm{N}$ máximo de $12,9 \mathrm{~g} \mathrm{~kg}^{-1}$ com a dosagem de $8 \mathrm{t} \mathrm{ha}^{-1}$ de $\mathrm{CaCO}_{3}$ (Figura $3 \mathrm{c})$. Provavelmente, a calagem mesmo superficial, conseguiu mineralizar nitrogênio, melhorando o aproveitamento do nutriente pelas plantas de gladíolo. Rosolem et al. (2003), estudando a dinâmica do $\mathrm{N}$ em razão da calagem em plantas de algodoeiro, concluiu que a calagem aumentou a mineralização e a nitrificação do N que, uma vez disponibilizado, as plantas podem absorvê-lo.

Doses de calcário superiores a $8 \mathrm{t} \mathrm{ha}^{-1}$ poderiam possibilitar maior absorção de nitrogênio pelas plantas de gladíolos; entretanto, essa dose foi desfavorável à absorção de $\mathrm{K} \mathrm{e} \mathrm{Mg}$ (Figura 3a e b) e estes nutrientes são responsáveis pela qualidade da haste floral (Tombolato, 2004).

Com base nos resultados obtidos pode-se concluir que as doses de calcário e potássio estudadas não foram eficientes para produzir plantas de gladíolo classificadas comercialmente como extra.

Quanto aos teores nutricionais, a calagem e as doses de $\mathrm{K}_{2} \mathrm{O}$ não interferiram nos teores de Ca nas plantas; a ausência de calagem e a dose máxima de $\mathrm{K}_{2} \mathrm{O}$ propiciaram aumento dos teores de K na planta; doses superiores a 58,7 $\mathrm{kg} \mathrm{ha}^{-1} \mathrm{de} \mathrm{K}_{2} \mathrm{O}$ e superiores a 5,90 $\mathrm{t} \mathrm{ha}^{-1}$ de $\mathrm{CaCO}_{3}$ reduziram a absorção de $\mathrm{Mg}$ e, doses superiores a $88 \mathrm{~kg} \mathrm{ha}^{-1} \mathrm{de} \mathrm{K}_{2} \mathrm{O}$ prejudicaram a absorção de $\mathrm{N}$ enquanto que a utilização de 2,05 tha- $\mathrm{de}^{-1} \mathrm{CaCO}_{3}$ a favoreceu.

\section{AGRADECIMENTOS}

À Coordenação de Aperfeiçoamento de Pessoas de Nível Superior (CAPES), pela concessão de bolsa de Mestrado à primeira autora.

\section{REFERÊNCIAS}

BONGERS FJG. 2000. Informativo IBRAFLOR. Holambra. $10 \mathrm{p}$

BORGES EM. 2005. Rendimento, qualidade e precocidade de gladiolo irrigado no Recôncavo Baiano. Cruz das Almas: UFBAEscola de Agronomia. 64p. (Dissertação mestrado).

BOYLE RL; UCHÔA SCP; SANTOS CSV; ALVES JMA; ALBUQUERQUE JAA; MARTINS SA. 2009. Introdução e avaliação de gladíolos em ambiente de cerrado no Estado de Roraima.RevistaAgro@ambiente On-line 3: 36-41.

GUIMARÃES MC; PAIVA PDO; FERREIRA CA; CARVALHO JG; PAIVA R. 2005. Efeito da aplicação de diferentes níveis de boro e adubo orgânico no desenvolvimento da cultura do gladíolo. In: CONGRESSO BRASILEIRO DE FLORICULTURA E PLANTAS ORNAMENTAIS, 15. Horticultura Brasileira, 23 (2), Resumo.... Fortaleza, SOB (CD-ROM).
JUNQUEIRA AH; PEETZ MS. 2011. 2010: Balanço do comércio exterior da floricultura brasileira. Hórtica- Contexto \& Perspectivas. Disponível em http://www.ibraflor.com/ publicacoes/vw.php?cod=160. Acesso em: 04 de novembro de 2011.

KARAGÜZEL O; ALTAN S; DORAN I; SOGUIR Z. 1999. The effects of $\mathrm{GA}_{3}$ and additional $\mathrm{KNO}_{3}$ fertilisation on flowering and quality characteristics of Gladiolus grandiflorus 'eurovision'. Developments In Plant and Soil Sciences 86: 259-262.

KÖPPEN W. 1948. Climatologia: con un estudio de los climas de la tierra. Cidade do Mexico: Fondo de Cultura Econômica. 478p.

MALAVOLTA EA; VITTI GC; OLIVEIRA AS. 1997. Avaliação do estado nutricional das plantas: princípios e aplicações. Piracicaba: Potafós. 201p.

MARSCHNER H. 1995. Mineral nutrition of higher plants. London: Academic Press. 889p.

MASCARENHAS HAA; TANAKA RT; CARMELLO QAC; GALLO PB; AMBROSANO GMB. 2000. Calcário e potássio para a cultura da soja. Scientia. Agricola 57: 445-449.

MEDEIROS JC; ALBUQUERQUE JA; MAFRA AL; ROSA JD; GATIBONI LC. 2008. Relação cálcio: magnésio do corretivo da acidez do solo na nutrição e no desenvolvimento inicial de plantas de milho em um Cambissolo Húmico Álico. Semina: Ciências Agrárias 29: 799-806p.

PAIVA, PDO. 1999. Cultura do gladiolo. Lavras: UFLA- Departamento de Agricultura. 12p.

PONTES ASC; ROCHA RC; SANTOS JC. 2005. Produção e qualidade de flores de gladíolos em função da adubação orgânica, mineral e organo-mineral. In: CONGRESSO BRASILEIRO DE OLERICULTURA, 45. Horticultura Brasileira, 23 (2), Resumos... Fortaleza: SOB (CD-ROM).

ROSA YBCJ; ROSA JUNIOR EJ; PEIXOTO PPP; ZARATE NAH; GANCEDO M. 2009. Interação nitrogênio, calcário e gesso agrícola para o cultivo da planta ornamental gladíolo. Magistra 21: 311-320.

ROSOLEM CA; FOLONI JSSE; OLIVEIRA RH. 2003. Dinâmica do nitrogênio no solo em razão da calagem e adubação nitrogenada, com palha na superfície. Pesquisa Agropecuária Brasileira 38: 301-309.

RUPPENTHAL V; CASTRO AMC. 2005. Efeito do composto de lixo urbano na nutrição e produção de gladíolo. Revista Brasileira Ciência do Solo 29: 145-150.

SAIRAM RK; VASANTHAN B; ARORA A. 2011. Calcium regulates gladiolus flower senescence by influencing antioxidative enzymes activity. Acta Physiol Plant 33: 1897-1904.

TOMBOLATO AFC. 2004. Cultivo comercial de plantas ornamentais. Campinas: Instituto Agronômico. 211p.

ZUBAIR M; AYUB G; WAZIR FK; KHAN M; MAHMOOD Z. 2006. Effect of potassium on preflowering growth of gladiolus cultivars. Journal of Agricultural and Biological Science 1: 36-46. 